SISTEMA
ELETRÔNICO
DE REVISTAS
SER I UfPR

\title{
Valor agregado em Sistemas Agroindustriais Familiares de Base Ecológica (SAFEs)
}

\section{Value added in Ecological Based Family Agro-industrial Systems (SAFEs)}

\author{
Marcio GAZOLLA ${ }^{1 *}$, Arlindo Jesus Prestes de LIMA ${ }^{2}$, Carolina BRIGNONI ${ }^{3}$ \\ ${ }^{1}$ Programa de Pós-Graduação em Desenvolvimento Regional (PPGDR), Universidade Tecnológica Federal do Paraná (UTFPR), Pato Branco, \\ PR, Brasil. \\ ${ }^{2}$ Universidade Federal de Santa Maria (UFSM), Frederico Westphalen, RS, Brasil. \\ ${ }^{3}$ Universidade Federal do Rio Grande do Sul (UFRGS), Porto Alegre, RS, Brasil. \\ *E-mail de contato: marciogazolla1@gmail.com
}

Artigo recebido em 10 de abril de 2017, versão final aceita em 31 de outubro de 2018.

O objetivo do estudo foi avaliar economicamente o valor agregado em Sistemas Agroindustriais Familiares de Base Ecológica (SAFEs), tanto no que tange a produção in natura como transformada (agroindustrializada) com formatos orgânicos. As questões de pesquisa que serviram de guia à investigação foram: a) quanto de valor agregado é gerado em uma unidade de produção agroindustrial ecológica? b) qual o valor agregado do sistema de produção agroindustrial e nas diferentes cadeias produtivas ecológicas? Para atingir este objetivo e responder as questões, utilizou-se de um enfoque teórico baseado na avaliação de desempenho econômico dos sistemas de produção. Em relação à metodologia, foram pesquisadas doze unidades de produção ecológicas, que produzem e processam alimentos na Região Norte do Estado do Rio Grande do Sul. Os resultados evidenciam que estes sistemas produtivos possuem menores custos de produção, comparativamente, a outras experiências da agricultura brasileira e gaúcha por um lado e, de outro, conseguem gerar maiores níveis de valor agregado e de rentabilidade às famílias e às diferentes cadeias produtivas analisadas, por associarem produção ecológica in natura com agroindustrialização.

Palavras-chave: valor agregado; sistema agroindustrial; cadeias produtivas ecológicas; desenvolvimento rural e regional.

ABSTRACT: The objective of the study was to economically evaluate the value in Family Agro-industrial Systems of Ecological Basis (SAFEs), both with respect to production in nature and as transformed (agro-industrialization) with organic shapes. The research questions that guided the investigation were: a) How much of the value is generated in an environmentally friendly agro-industrial farm? b) What is the value of the agro-industrial 
production system and the different ecological supply chains? To achieve this goal and answer the questions, we used a theoretical approach supported on the evaluation of economic performance of production systems. Regarding the methodology, twelve ecological production units were surveyed, which produce and process foods in the Northern Region of the State of Rio Grande do Sul. The results show that these production systems have lower production costs compared to other experiences of Brazilian and Gaucho agriculture on the one hand and, on the other, they can generate higher levels of added value and profitability families and different supply chains analyzed by associating ecological production in natura with agro-industrialization.

Keywords: added value; agro-industrial system; ecological production chains; rural and regional development.

\section{Introdução}

O sistema agroalimentar tem-se reproduzido predominantemente na forma de alimentos industrializados, dietas desbalanceadas, mercados monopolizados e às vezes sofrendo crises, por exemplo, quando das adulterações do leite no Sul do país ou mesmo o mal da "vaca louca" na Europa (Friedmann, 2005; McMichel, 2009). Os alimentos orgânicos parecem possuir, grosso modo, um duplo papel dentro deste sistema: de um lado, estão sendo usado por atores, grandes grupos empresariais e varejistas para apoiar a reprodução do sistema agroalimentar vigente, incrementando-o, o que tem sido denominado de "convencionalização" (Guthman, 2004; Niederle et al., 2013), de outro, estes alimentos buscam formatos sociotécnicos "alternativos" dentro do sistema agroalimentar, sendo fundamentais a atores que possuem valores e representações sociais diferentes em relação à saúde, alimentação saudável e reequilíbrio ambiental com os recursos do planeta (Lang, 2005; Morgan \& Sonino, 2010).

Embora haja muitas faces e controvérsias sobre os papéis dos alimentos orgânicos no sistema agroalimentar, os mesmos são uma realidade sedimentada. No Brasil os dados do Censo Agro- pecuário (IBGE, 2006) evidenciam que 90.498 estabelecimentos agropecuários fazem este tipo de produção, representando $1,75 \%$ do total de estabelecimentos existentes. Os principais grupos de atividades onde esta produção está presente são na produção de animais $(42,01 \%)$, lavouras temporárias $(33,34 \%)$, lavouras permanentes $(10,56 \%)$, horticultura e floricultura $(9,83 \%)$, dentre outras atividades (produção florestal, pesca, aquicultura). Na Região Sul do país, os dados do Censo mostram quase 20 mil unidades produtivas (19.276 estabelecimentos) que praticam a agricultura orgânica, o que representa $1,92 \%$ sobre o total dos estabelecimentos agropecuários existentes.

Uma das questões normalmente levantadas nas discussões sobre a produção de orgânicos é que a mesma possui maior valor agregado, se comparada a outros tipos de produções agroalimentares, por exemplo, a produção de grãos. Isso é atribuído a diversos fatores, desde o preço prêmio recebido pelos orgânicos nos mercados (Touzard, 2010) e a transformação destes por agroindústrias adicionaria maior valor aos alimentos (Mior, 2005), passando pelos atributos ambientais e de saúde presentes nestes produtos (Niederle et al., 2013), até argumentos que levam em conta representações sociais pouco tangíveis dos consumidores como os que mencio- 
nam a "superioridade qualitativa e nutricional" (Oliveira et al., 2002). Entretanto, não existem estudos que conseguiram demonstrar: a) quanto de valor agregado é gerado em uma unidade agroindustrial ecológica? b) qual o valor agregado do sistema de produção agroindustrial ou mesmo nas diferentes cadeias produtivas ecológicas?

É no sentido das questões destacadas a cima que este trabalho quer contribuir no avanço dos conhecimentos da área. O objetivo é avaliar economicamente o valor agregado em Sistemas Agroindustriais Familiares de Base Ecológica (SAFEs), tanto no que tange a produção in natura como transformada em agroindústrias com formatos orgânicos e/ou agroecológicos. Neste intuito, o trabalho avaliou o valor agregado e os custos de produção de doze experiências, na Região Norte do Estado do Rio Grande do Sul (espacialização da Regional da EMATER de Frederico Westphalen/RS), no ano de 2014. As iniciativas investigadas são de diversas cadeias produtivas, o que traz riqueza empírica e analítica aos dados, já que a dinâmica e os valores apurados da produção ecológica variam por cadeia de produção ou alimento analisado.

Denomina-se de SAFE as experiências investigadas devido a três motivos. Primeiro por dar uma ideia de análise sistêmica e integrada dos sistemas de produção das unidades produtivas. Segundo, devido ao fato de pesquisarem-se formas sociais familiares de produção e trabalho nos espaços rurais, onde a administração e decisões são estrategicamente tomadas pelo grupo doméstico, de forma proativa. Terceiro, pela análise conduzida elucidar a dinâmica ecológica e econômica de produção tanto de aspectos ligados as matérias primas como dos alimentos transformados pelas famílias.

O trabalho está estruturado em quatro partes essenciais, além da introdução e algumas considerações finais. Na primeira explicita-se a metodologia de cálculo estatístico usada para aferir o valor agregado e custos de produção das experiências. $\mathrm{Na}$ segunda discute-se teoricamente a noção de SAFE e de valor agregado agroalimentar, segundo alguns aspectos e estudos já realizados. Na terceira seção são caracterizadas as doze experiências investigadas. Nas duas últimas seções são apresentados os resultados do trabalho utilizando-se da estatística descritiva e comparações de indicadores econômicos das cadeias de produção ecológicas.

\section{Metodologia de pesquisa e de cálculo do valor agregado}

A metodologia de pesquisa possuiu várias etapas. Primeiro, elaborou-se o roteiro de pesquisa semiestruturado o qual continha as principais questões da avaliação econômica dos SAFEs, dividindo as perguntas segundo os dois subsistemas a analisar: produção primária e agroindustrial ${ }^{1}$. A segunda

\footnotetext{
${ }^{1}$ A opção em manter os cálculos integrados destes dois subsistemas é devido à dificuldade do ponto de vista do levantamento dos dados em separar custos e, consequentemente, rendas/valor agregado dos dois subsistemas, já que os agricultores familiares fazem uma contabilidade integrada da unidade de produção (o que o Chayanov chamava de "cálculo econômico subjetivo"). Por isso, as atividades dos subsistemas in natura estão conectadas com o subsistema agroindustrial, ficando difícil separar os dados de avaliação econômica. São processos contábeis e reprodutivos complexos, em que os agricultores sabem, por exemplo, o valor da conta mensal de energia, mas a separação dos custos com energia entre os seus diferentes usos (casa da família, ordenha das vacas e processamentos dos derivados do leite) eles não sabem informar exatamente. Por outro lado, o pesquisador não pode, de forma arbitrária, fazer a separação destes custos produtivos, pois poderá induzir erros de cálculos em atribuir valores a cada subsistema (e a família), podendo comprometer a 'veracidade' dos dados.
} 
etapa consistiu na identificação das experiências e serem investigadas. A amostra foi dirigida e intencional já que se procuravam iniciativas que estivessem em processo de transição ecológica ou já consolidadas na produção orgânica.

Para isso, contou-se com a ajuda do Escritório Regional da EMATER de Frederico Westphalen/ $\mathrm{RS}$, que indicou possíveis iniciativas com as características requeridas, nos 42 municípios de sua abrangência. Foram identificadas quinze experiências potenciais de serem entrevistadas; contudo, três declinaram da entrevista. Restaram doze, que foram investigadas, conforme são apresentados na seção de caracterização das iniciativas.

A metodologia de avaliação econômica dos sistemas ecológicos seguiu o roteiro de cálculos para avaliação de sistemas de produção, propostos por Mazoyer \& Roundart (2001) e Lima et al. (1995). No Quadro 1 é possível visualizar a sequência lógica de cálculos desenvolvidos na pesquisa. Primeiro foi calculado o Valor Agregado (VA), através da subtração do Consumo Intermediário (CI) e das Depreciações (D) do Produto Bruto (PB). $\mathrm{O}$ segundo passo foi calcular o Valor Agregado Bruto (VAB), descontando-se do PB o valor do CI. Também, calculou-se o Valor Agregado Líquido (VAL), descontando-se do VAB os valores relativos às depreciações (D).

QUADRO 1 - Sequência de passos para desenvolver os cálculos dos indicadores econômicos.

$$
\begin{aligned}
& \mathrm{VA}=\mathrm{PB}-\mathrm{CI}-\mathrm{D} \\
& \mathrm{VAB}=\mathrm{PB}-\mathrm{CI} \\
& \mathrm{VAL}=\mathrm{VAB}-\mathrm{D} \\
& \mathrm{RAI}=\mathrm{VA}-\mathrm{DVA}
\end{aligned}
$$

FONTE: Adaptado de Lima et al. (1995).
$\mathrm{Na}$ terceira etapa de cálculos, obteve-se a Renda Agroindustrial (RAI), da dedução dos valores do VA da Divisão do Valor Agregado (DVA). Todos os dados e cálculos desenvolvidos foram embasados em informações anuais (janeiro a dezembro de 2014). Todos os conceitos destes indicadores econômicos dos sistemas ecológicos podem ser entendidos a partir do Quadro 2, que apresenta as definições dos mesmos.

Os indicadores econômicos, técnicos e produtivos foram primeiramente calculados em planilhas individuais para cada experiência, utilizando o Software Microsoft Excel. Posteriormente, os principais dados estatísticos das doze iniciativas foram agrupados em um banco agregado, no qual se fez as análises referentes à estatística descritiva, comparações de indicadores e outras análises que estão apresentadas nas duas últimas seções que trazem os resultados do trabalho.

\section{A noção de Sistemas Agroindustriais \\ Familiares de Base Ecológica (SAFEs) e de valor agregado agroalimentar}

O SAFE é uma noção proveniente da Teoria Geral dos Sistemas, segundo a qual há diferentes sistemas interligados (políticos, econômicos, produtivos, sociais, tecnológicos, etc.), dispostos em diferentes níveis da sociedade (Vasconcellos, 2006). No caso da agricultura e do desenvolvimento rural fala-se da existência de sistemas agrários (Mazoyer \& Roundart, 2001). Dentre os sistemas agrários, o trabalho enfoca os SAFEs, que são definidos como um tipo específico e um misto de sistemas familia- 
res de produção de alimentos, produtos e matérias primas in natura e de transformação agroindustrial de produtos agropecuários, possuindo como base os processos ecológicos de produção e processamento.

Neste sentido, o SAFE é formado por dois subcomponentes essenciais. O primeiro, o subsistema familiar de produção de matérias primas e alimentos in natura. Este subsistema estrutura-se a partir dos elementos tecnológicos, produtivos, força de trabalho familiar e meios de produção disponíveis. Nele está contida a produção agropecuária e de alimentos que serve de base ao desenvolvimento do subsistema agroindustrial, como já evidenciaram outros estudos (Mior, 2005; Maluf, 2004; Gazolla, 2013).
O segundo, o subsistema agroindustrial é aquele que processa o conjunto de matérias primas produzidas pelo primeiro subsistema, transformando-as em alimentos e produtos elaborados de maior valor agregado para serem comercializados em mercados, especialmente locais e cadeias curtas agroalimentares (Renting et al., 2003; Gazolla \& Schneider, 2017). No subsistema agroindustrial, as matérias primas a serem processadas são essencialmente provenientes das próprias unidades familiares, embora, em alguns casos, este se abastece comprando matérias primas de outros fornecedores (Lima et al., 1995) ${ }^{2}$.

QUADRO 2 - Principais conceitos dos indicadores econômicos dos sistemas produtivos.

\begin{abstract}
Depreciação (D): A depreciação é um custo produtivo que os agricultores possuem com o desgaste de sua infraestrutura produtiva, especificamente seus capitais fixos, que tendem a perder valor pelo uso, tempo de vida e obsolescência tecnológica.

Consumo Intermediário (CI): São todos os custos com insumos e serviços que adentram o processo de produção das unidades produtivas, excetuando-se os custos com a força de trabalho. São bons exemplos de desembolsos com consumo intermediário a aquisição de sementes, corretivos do solo, rações, entre outros.

Divisão do Valor Agregado (DVA): São todos os custos associados ao pagamento de serviços, empréstimos, arrendamentos, juros, impostos e força de trabalho contratada na unidade de produção. Possui este nome, por que na prática, o agricultor divide sua riqueza gerada com os demais agentes econômicos e produtivos da sociedade e do Estado.

Produção Bruta (PB): É obtida a partir da multiplicação das quantidades físicas de cada produto com seu respectivo preço. Exceção é a produção para autoconsumo, em que foram usados os dados médios por estabelecimento do RS, com base no Censo Agropecuário do IBGE (2006).

Valor Agregado (VA): É definido como o valor da produção bruta restante, depois de descontados desta as parcelas do consumo intermediário e depreciações. O valor agregado indica o quanto um sistema produtivo consegue gerar de riqueza, a partir da conjugação dos seus fatores de produção (recursos naturais, capital, força de trabalho e tecnologia). Este indicador também pode ser calculado em termos brutos e líquidos (VAB e VAL).

Renda Agroindustrial (RAI): Representa a parcela do valor agregado que resta, após ser subtraído deste os valores da divisão do valor agregado. Também pode ser conceituado, alternativamente, como o excedente econômico retido, depois de descontado da produção bruta os custos totais de produção (fixos + variáveis) de um sistema produtivo. É a parcela de recursos financeiros sobrantes ao agricultor, geralmente utilizada para reproduzir a família e reinvestir na unidade de produção (ecológica).

Ponto de Nivelamento (PN): É definido como a quantidade da produção bruta necessária para cobrir os custos de produção "variáveis" do sistema produtivo e/ou da unidade; dito de outra forma é o valor monetário de produção bruta necessária para pagar os gastos com DVA e CI do processo produtivo ecológico.

Nível de Reprodução Simples (NRS): É atribuir custo de oportunidade a força de trabalho presente na unidade, de forma que se possa comparar rendimentos auferidos na produção de alimentos e produtos, com os valores que este mesmo trabalhador receberia, por exemplo, em um emprego urbano, recebendo um salário mínimo mensal por Unidade de Trabalho Homem ocupada (UTH).
\end{abstract}

FONTE: Adaptado de Lima et al. (1995). ${ }^{2}$ Para entender mais aprofundadamente a ideia de existência de sistemas e subsistemas no caso da administração de unidades familiares na
agricultura, ver Lima et al. (1995). 
Tanto no primeiro subsistema como no segundo, analisam-se unidades familiares, em que o trabalho e administração das mesmas são realizados pela família de forma conjunta, seguindo a distinção clássica ente os elementos presentes na unidade de produção (sistemas produtivos, tecnologias, meios de produção, posse da terra, entre outros) e grupo doméstico (relações sociais familiares, parentesco, comunitárias, sociabilidade e reciprocidade) (Schneider, 2003; Wanderley, 2009).

Outro aspecto comum aos SAFEs é que estes se desenvolvem a partir de técnicas produtivas e conhecimentos presentes no que autores tem denominado de agricultura de base ecológica (Altieri, 2004; Glissman, 2009). Dentro deste enfoque, tanto a produção de matérias primas, produtos agropecuários e alimentos do subsistema in natura quanto as técnicas e processos de transformação presentes no subsistema agroindustrial seguem os princípios da agricultura de base ecológica. Dessa maneira, os SAFEs são sistemas de produção menos intensivos em uso de insumos externos, tecnologias, meios de produção e conhecimentos exógenos (Ploeg, 2008).

No caso das experiências de SAFEs investigadas neste trabalho, usa-se denominá-las "em processo de transição ecológica". Isto é para mostrar que as iniciativas estão em um movimento social e técnico que envolve evoluções e mudanças de sistemas produtivos intensivos, em alguns casos, seguiam os princípios da modernização da agricultura, em direção a um conjunto de práticas agropecuárias mais sustentáveis do ponto de vista do meio ambiente, saúde, processos produtivos agroalimentares e dos mercados que constroem. $\mathrm{Na}$ literatura internacional este processo histórico de mudanças sociotécnicas tem sido chamado de transição agroecológica (Altieri, 2004; Glissman,
2009). Denomina-se dessa forma as iniciativas de SAFEs pesquisadas por elas estarem em diferentes níveis de avanço no processo de transição ecológica.

Nestes SAFEs as matérias primas, produtos e alimentos produzidos, de forma geral, possuem altos níveis de valor agregado. Na literatura já existente, a qual se faz menção de seguir de alguns estudos, o valor agregado possui uma gama de elementos que o estruturam. O primeiro está ligado aos aspectos de qualidade ambiental que estes produtos oferecem aos mercados e consumidores, onde a certificação orgânica e o preço prêmio têm sido considerados definidores de valorações sociais e econômicas destes produtos (Niederle et al., 2013). Em outros casos, o próprio conhecimento tácito dos consumidores e suas relações diretas com os produtores é referência suficiente para pagar-se mais por estes alimentos (Darolt, 2013).

Outro aspecto a ser considerado são os atributos ligados à agricultura familiar e colonial no Sul do país que seriam "transferidos" aos alimentos, de forma que sua história, modo artesanal de produção, conhecimentos e características dessa forma social de produção e trabalho nos espaços rurais estaria presente em seus produtos, "adicionando" um valor extra aos seus alimentos, que é reconhecido e internalizado pelos consumidores (Oliveira et al., 2002). Conceitualmente, na literatura, isso é chamado de valor social (Long, 2001).

Outro elemento importante associado à agregação de valor nos SAFEs é que os agricultores mantem o controle de todos (ou quase todos) os elos da cadeia de produção, não necessitando de intermediários e outros atores sociais que se apropriariam do valor agregado. É comum às famílias serem semiautônomas sobre os processos de produção das matérias-primas - processamento 
dos derivados - administração da unidade de produção - e, comercializarem seus próprios produtos e alimentos em mercados locais, regionais e cadeias curtas de abastecimento (Gazolla, 2013).

Associado a isso, como outro elemento, há um processo de produção e construção de mercados que envolvem um estilo de agricultura que na literatura internacional tem sido denominada de econômica (Ploeg, 2008). São práticas agrícolas e de processamento de alimentos baseadas na redução dos custos de produção e transação ao longo de toda a cadeia de transformação, de forma que estes valores fiquem em poder dos agricultores. Isso acontece muito em SAFEs que possuem a agricultura de base ecológica como diretriz.

Outro aspecto a considerar, que agrega valor aos alimentos, são as transformações que as matérias primas sofrem nos processos de agroindustrialização. Embora na produção in natura já haja um processo de agregação de valor, pois já há a conjugação de diferentes fatores de produção (recursos naturais, capital, tecnologia e força de trabalho), que geram produtos e alimentos com maior valor; é na transformação agroindustrial que isso ocorre com maior destaque, dada a multiplicidades de elaborações que as matérias primas podem sofrer (processamentos físicos, biológicos, químicos, enzimáticos, ambientais, entre outros). Isso faz que a agroindustrialização de base ecológica gere altos níveis de valor agregado as unidades familiares (Lima et al., 1995).

Como último elemento que estes SAFEs específicos possuem, estão os atributos territoriais e locais que os fazem auferirem altos níveis de valor agregado aos produtos. A literatura relata como aspectos importantes à geração de valor agregado características como o tipo de recursos naturais, agroecossistemas, história local, tradições gastronômicas e culinárias, identidade social dos atores, entre outras "âncoras territoriais". Estes aspectos seriam os definidores da qualidade dos alimentos que, em alguns casos, são chamados de produtos típicos locais (Marescotti, 2006) e, em outros, são capturados pelas noções e/ou normativas do Estado sobre indicações geográficas ou de origem nos mercados agroalimentares (Niederle et al., 2013).

Uma última coisa importante a ressaltar é que nos SAFEs os processos de agregação de valor não são estanques, ou seja, eles não ocorrem somente por uma destas estratégias descritas a cima. $\mathrm{Na}$ maioria das vezes há mais de uma forma de valor agregado sendo posta em prática pelos atores sociais, de forma muito proativa e conjugada. Por exemplo, nos casos analisados é muito comum encontrar-se os valores ambientais juntamente com as transformações agroindustriais a que os produtos e alimentos passam em suas elaborações.

\section{Breve caracterização das experiências investigadas}

Na Tabela 1 tem-se o ano de origem, localização espacial das iniciativas pesquisadas e suas respectivas áreas de terras. Nota-se que uma parte das experiências possui sua origem nos anos de 1990, tendo em torno de duas décadas de existência. Outras são do inicio deste século ou próximas ao ano de 2010, sendo bem mais recentes. A área média das experiências é de 18,07 ha, comprovando que os SAFEs são desenvolvidos em pequenas propriedades rurais familiares.

A Tabela 2 apresenta outros indicadores relacionados à força de trabalho das propriedades 
rurais e seus diferentes usos (agroindústria, venda dos produtos e alimentos e destinado à produção primária). O número total de Unidades de Trabalho Homem (UTHs)é de 41, existindo, em média, 3,42UTHs/SAFE, podendo ser força de trabalho familiar (na maioria dos casos) ou contratados e sócios, embora haja casos em que este número é menor, sendo formado apenas pelo casal (2 UTHs), ou maior, até 4UTHs, no caso de iniciativas de ação coletiva como é o caso do SAFE $8^{3}$.

Na mesma Tabela é possível observar o total de horas de trabalho anuais nos SAFEs, que foram de 107.220 horas por ano, sendo que em média, cada um dos sistemas de base ecológica mobilizou
7.935,00 horas anuais de trabalho. Estes totais de horas trabalhadas foram divididas entre as atividades de agroindustrialização, comércio dos alimentos e trabalho na produção das matérias primas. De maneira geral, nota-se uma predominância de horas trabalhadas nas atividades de transformação dos alimentos, ficando em média com quase a metade de todo o tempo de trabalho gasto (46,71\%). Grosso modo, este dado demonstra que nos SAFEs a principal atividade em termos de ocupação da força de trabalho é a agroindustrialização.

Já a atividade de comercialização dos alimentos e produtos dos SAFEs fica, em média, com $19,51 \%$ do tempo de trabalho disponibilizado

TABELA 1 - Ano de origem, localização e área de terras dos SAFE pesquisados.

\begin{tabular}{lccc}
\hline SAFEs & Ano de Origem & Municípios (RS) & Área (Ha) \\
\hline SAFE 1 & 2009 & Frederico Westphalen & 4,7 \\
SAFE 2 & 2010 & Cristal do Sul & 12,5 \\
SAFE 3 & 1987 & Seberi & 13,5 \\
SAFE 4 & 2012 & Iraí & 9,2 \\
SAFE 5 & 2000 & Constantina & 4,0 \\
SAFE 6 & 2012 & Constantina & 10,5 \\
SAFE 7 & 2008 & Erval Seco & 23,6 \\
SAFE 8 & 1998 & Nonoai & 5,0 \\
SAFE 9 & 2005 & Alpestre & 15,0 \\
SAFE 10 & 2011 & Frederico Westphalen & 8,8 \\
SAFE 11 & 1987 & Caiçara & 45,0 \\
SAFE 12 & 1997 & Novo Barreiro & 55,0 \\
\hline Média & & & $\mathbf{1 8 , 0 7}$ \\
\hline
\end{tabular}

FONTE: Pesquisa de campo (2015).

${ }^{3}$ Uma Unidade de Trabalho Homem (UTH) é igual a um homem adulto, trabalhando 8 horas por dia, durante 300 dias úteis no ano (Hoffman et al., 1989). 
TABELA 2 - Força de trabalho e total de horas trabalhadas/anos nos SAFEs e sua repartição estre as atividades na agroindústria, comércio e produção primária.

\begin{tabular}{|c|c|c|c|c|c|}
\hline SAFEs & UTHs & $\begin{array}{c}\text { Total de Horas } \\
\text { (Hs/a) }\end{array}$ & $\begin{array}{c}\text { Agroindústria } \\
(\%)\end{array}$ & $\begin{array}{c}\text { Comércio } \\
(\%)\end{array}$ & $\begin{array}{c}\text { Produção primá- } \\
\text { ria }(\%)\end{array}$ \\
\hline SAFE 1 & 2 & 3.900 & 24,23 & 60,00 & 15,77 \\
\hline SAFE 2 & 3 & 6.600 & 47,27 & 27,27 & 25,45 \\
\hline SAFE 3 & 4 & 9.600 & 45,75 & 12,00 & 42,00 \\
\hline SAFE 5 & 4 & 8.400 & 34,29 & 8,57 & 57,14 \\
\hline SAFE 6 & 2 & 4.800 & 35,00 & 10,00 & 55,00 \\
\hline SAFE 7 & 2 & 4.800 & 41,25 & 17,50 & 41,25 \\
\hline SAFE 11 & 4 & 9.000 & 53,33 & 10,00 & 36,67 \\
\hline SAFE 12 & 6 & 13.800 & 44,78 & 29,13 & 26,09 \\
\hline Média & 3,42 & 7.935 & 46,71 & 19,51 & 34,00 \\
\hline
\end{tabular}

FONTE: Banco de Dados Agregado (2015).

pelas famílias. Entre as três atividades classificadas na Tabela 2, esta é a que menos ocupa tempo de trabalho. Isso é devido aos mercados e canais de comercialização serem locais e cadeias curtas de abastecimento, com pouco gasto de tempo para fazer as rotas e entregas de produtos. Em muitos casos, os próprios consumidores vêm buscar os alimentos ecológicos nas unidades produtivas das famílias (Gazolla, 2012). As atividades de produção primária ocupam os demais $34 \%$ do tempo de trabalho, ficando em $2^{\circ}$ posto.

Na Tabela 3 estão os principais produtos e alimentos in natura e agroindustrializados produzidos pelos SAFEs investigados. Pode-se notar a grande diversidade produtiva dos mesmos, em termos de mix de produtos e alimentos existentes. Os diferentes SAFEs produzem desde grãos, frutas, cana de açúcar, cereais de inverno, produtos de horta, erva mate e seus respectivos derivados vegetais (quando existem), bem como animais em geral como frangos, peixes, porcos, gado, abelhas e seus respectivos derivados e produtos obtidos a partir destes como mel, leite, carne e ovos, só para citar alguns ${ }^{4}$.

Na Tabela 3 também é possível visualizar as principais cadeias produtivas presentes em cada uma das experiências, que serão usadas na comparação de desempenho econômico entre si, nestas próximas seções de resultados do trabalho. 
TABELA 3 - Principais produtos e alimentos in natura e agroindustrializados dos SAFEs.

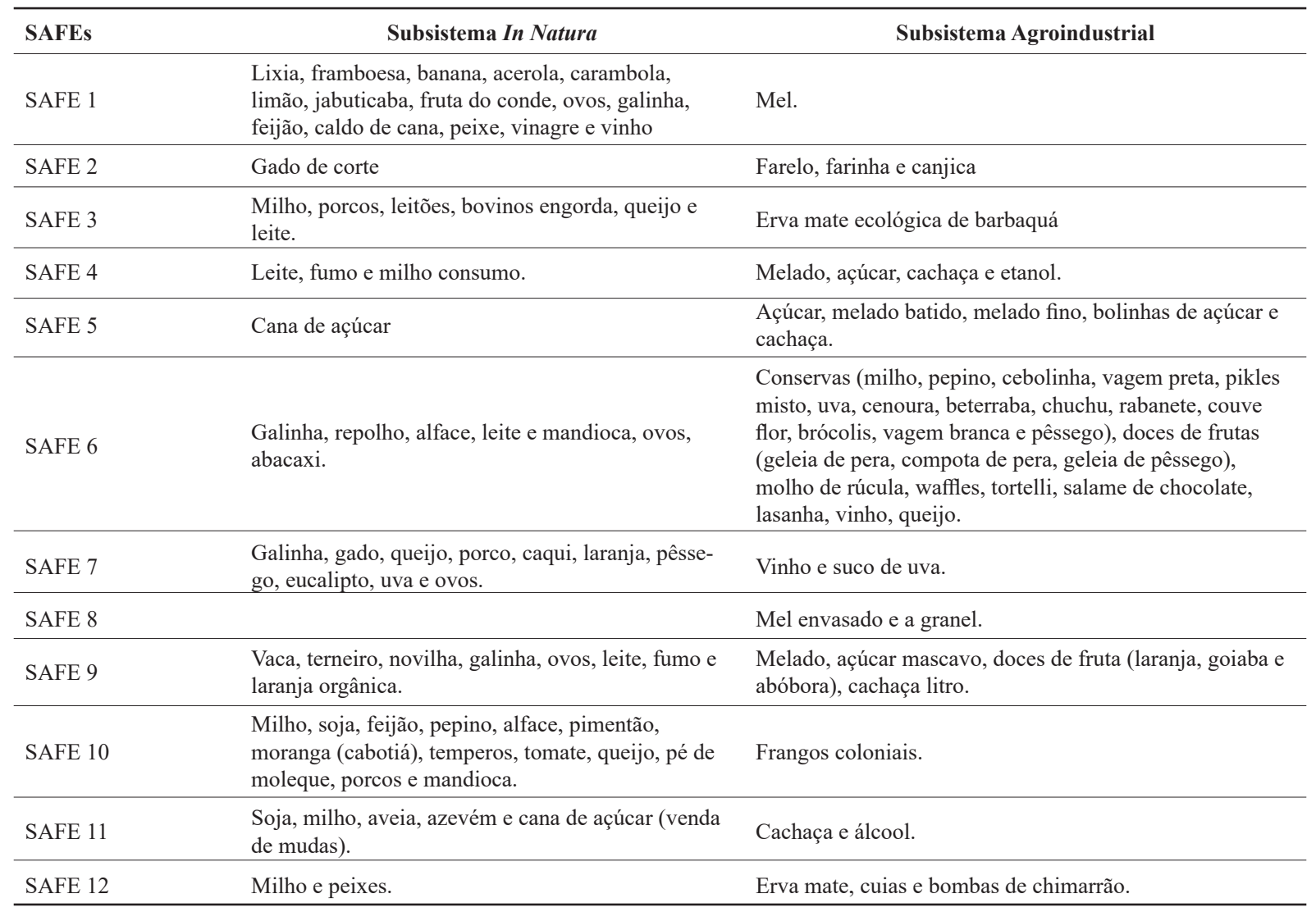

FONTE: Pesquisa de campo (2015).

\section{Custos de produção, valor agregado $e$ renda agroindustrial nos $S A F E S$}

O objetivo desta seção é analisar os dados sobre custos de produção, valor agregado e renda agroindustrial dos SAFEs pesquisados. Neste sentido, a Tabela 3 traz os dados sobre custos produtivos, como a depreciação (D), consumo intermediário (CI) e Divisão do Valor Agregado (DVA) das iniciativas, de forma absoluta e sobre o Custo Total (CT). Na Tabela
4 é possível observar que a depreciação média por SAFE é de $\mathrm{R} \$ 13.758,02$, sendo que a mesma chega a quase $25 \%$ dos custos totais de produção $(24,79 \%)$. Outro custo que os SAFEs possuem é o CI. Em média, o CI é de $\mathrm{R} \$ 111.468,33$, perfazendo quase $60 \%$ dos custos de produção das experiências $(58,31 \%)$ em relação ao custo total. Estes valores de CI são os maiores custos das experiências de produção de base ecológica, contudo, ainda são custos menores, se comparados ao da agricultura nacional. 
Neste sentido, as iniciativas familiares de base ecológica, possuem custos menores de CI do que as propriedades familiares brasileiras e da Região Sul. Estudo de Conterato et al. (2013) com base nos dados do Censo Agropecuário (IBGE, 2006) mostra que, para o Brasil como um todo, a agricultura familiar possui $78,00 \%$ de gastos com CI e as da Região Sul, em torno de $80,90 \%$ nesta rubrica. Isso reafirma a literatura internacional sobre o tema (Ploeg, 2008), que mostra a agricultura de base ecológica com práticas mais econômicas, é menos dependente dos mercados de insumos e serviços agropecuários externos as unidades (Altieri, 2004; Glissman, 2009).

$\mathrm{Na}$ Tabela 4 também é possível visualizar o terceiro conjunto de custos dos SAFES, os asso- ciados ao DVA. Segundo a Tabela 3, o DVA médio dos SAFEs é de R $\$ 19.559,17$, sendo quase 1/5 dos custos produtivos das iniciativas $(17,15 \%)$. Este é o menor dos três conjuntos de custos apurados junto às propriedades familiares.

A Tabela 5 apresenta os valores totais da Produção Bruta (PB) dos SAFEs, bem como a sua divisão em três tipos de PB: in natura, agroindustrialização com matérias primas próprias dos agricultores (AG-MPP) e com matérias primas compradas (AG-MPC). A PB total média por SAFE é de R\$250.497,70, porém, é um indicador que apresenta grande variação, pois há iniciativas com apenas R\$53.609,98 e, outras, com valores altos, que ultrapassam 1,3 milhão de reais/ano (R\$ $1.335 .409,98)$.

TABELA4 - Custos e percentuais sobre o Custo Total (CT) da Depreciação (D), Consumo Intermediário (CI) e Divisão do Valor Agregado (DVA).

\begin{tabular}{|c|c|c|c|c|c|c|}
\hline SAFEs & $\begin{array}{c}\text { Depreciação } \\
\text { (R\$) }\end{array}$ & D/CT (\%) & $\begin{array}{c}\text { CI } \\
\text { (R\$) }\end{array}$ & $\begin{array}{c}\text { CI/CT } \\
(\%)\end{array}$ & $\begin{array}{l}\text { DVA } \\
\text { (RS) }\end{array}$ & DVA/CT (\%) \\
\hline SAFE 1 & $8.745,60$ & 19,73 & $28.166,00$ & 63,55 & $7.411,79$ & 16,72 \\
\hline SAFE 3 & $10.973,00$ & 26,28 & $26.953,00$ & 64,56 & $5.120,32$ & 12,27 \\
\hline SAFE 6 & $1.332,60$ & 4,19 & $26.763,18$ & 84,07 & $3.739,70$ & 11,75 \\
\hline SAFE 7 & $11.418,00$ & 27,26 & $25.124,00$ & 59,98 & $5.344,33$ & 12,76 \\
\hline SAFE 8 & $5.745,00$ & 29,24 & $8.460,00$ & 43,05 & $5.445,00$ & 27,71 \\
\hline SAFE 12 & $32.295,00$ & 6,13 & $418.111,60$ & 79,35 & $76.539,70$ & 14,53 \\
\hline Média & $13.758,02$ & 24,79 & $111.468,33$ & 58,31 & $19.559,17$ & 17,15 \\
\hline
\end{tabular}

FONTE: Banco de Dados Agregado (2015). 
Na Tabela 5 é possível verificar a PB gerada com base no tipo de matéria prima usada. A matéria prima própria é predominante enquanto estratégia de agroindustrialização da produção de alimentos, ficando em média com R\$147.891,33/SAFE, o que corresponde, em percentuais, a mais da metade da matéria prima produzida pelas unidades familiares $(53,86 \%)$. Outros estudos com o tema da agroindústria rural conduzidos sobre os dados do Censo Agropecuário (Gazolla et al., 2012) e empíricos (Pelegrini \& Gazolla, 2008) também já haviam apontado a predominância da produção de matérias primas próprias pelos agricultores nos processos de transformação agroindustrial. Com essa prática, os agricultores mantem sua autonomia de gestão sobre a produção primária, bem como diminuem seus custos de produção, caso tivessem que adquirir estas nos mercados.

Já a produção in natura, aquela que não sofreu transformações agroindustriais e foi comercializada dessa forma é responsável por R \$ 49.185,85/experiência, o que corresponde a quase $30 \%$ da $\mathrm{PB}$ das propriedades $(29,26 \%)$. Se este percentual é somado ao anterior da matéria prima própria agroindustrializada, chega-se a $83,12 \%$ da PB que é gerada a partir das matérias primas produzidas pelos próprios agricultores, evidenciando uma estratégia de manterem sua autonomia interna as propriedades em relação à produção, característica típica da agricultura familiar e de base ecológica (Ploeg, 2008).

O valor comprado de matéria prima pelas agroindústrias é de R\$138.046,40, que correspon-

TABELA5 - Valor total da Produção Bruta (PB) e sua divisão em In natura, Agroindústria com Matéria Prima Própria (AG-MPP) e Agroindústria com Matéria Prima Comprada (AG-MPC).

\begin{tabular}{|c|c|c|c|c|c|c|c|}
\hline SAFEs & $\begin{array}{c}\text { Valor PB } \\
\text { (R\$) }\end{array}$ & $\begin{array}{c}\text { In natura } \\
\text { (R\$) }\end{array}$ & $\begin{array}{c}\text { In nat. } \\
(\%)\end{array}$ & $\begin{array}{c}\text { AG-MPP } \\
\text { (R\$) }\end{array}$ & $\begin{array}{c}\text { AG-MPP } \\
(\%)\end{array}$ & $\begin{array}{c}\text { AG-MPC } \\
(\mathrm{R} \$)\end{array}$ & $\begin{array}{c}\text { AG-MPC } \\
(\%)\end{array}$ \\
\hline SAFE 1 & $97.770,99$ & $42.770,99$ & 43,75 & $55.000,00$ & 56,25 & & 0,00 \\
\hline SAFE 3 & $113.530,98$ & $17.530,98$ & 15,44 & $96.000,00$ & 84,56 & & 0,00 \\
\hline SAFE 4 & $53.609,98$ & $33.849,98$ & 63,14 & $19.760,00$ & 36,86 & & 0,00 \\
\hline SAFE 6 & $55.940,99$ & $13.532,99$ & 24,19 & $14.346,00$ & 25,64 & $28.062,00$ & 50,16 \\
\hline SAFE 7 & $60.924,99$ & $29.924,99$ & 49,12 & $10.000,00$ & 16,41 & $21.000,00$ & 34,47 \\
\hline SAFE 8 & $94.680,00$ & & & $94.680,00$ & 100,00 & & 0,00 \\
\hline SAFE 12 & $656.394,99$ & $31.294,99$ & 4,77 & $24.960,00$ & 3,80 & $600.140,00$ & 91,43 \\
\hline Média & $250.497,70$ & $49.185,85$ & 29,26 & $147.891,33$ & 53,86 & $138.046,40$ & 16,89 \\
\hline
\end{tabular}

FONTE: Banco de Dados Agregado (2015). 
de a $16,89 \%$ da mesma, em média, sendo o menor percentual dos três averiguados. Note que menos da metade das iniciativas adquire matérias primas de fora do sistema produtivo. Se este percentual é somado ao da PB com matéria prima própria e é agroindustrializado, desprende-se que $70,75 \%$ da PB gerada nos SAFEs é proveniente de estratégias de agroindustrialização dos agricultores. Neste sentido, pode-se afirmar que a agroindustrialização é a principal responsável pela geração da PB destas unidades familiares ecológicas e, por conseguinte, por suas estratégias de reprodução econômicas.

A Tabela 6 apresenta os dados de Valor Agregado Bruto (VAB), Valor Agregado Líquido (VAL) e Renda Agroindustrial (RAI) em relação a PB dos SAFEs. Estes dados são fundamentais, pois permite verificar o quanto da PB resta depois de descontados os vários custos, conforme explicitado na seção dois do trabalho, onde discutiu-se a metodologia de cálculo. Segundo a Tabela 6, os SAFEs conseguem adicionar, em média, um VAB de R \$ 139.029,37. Isso representa que, depois de descontado da PB o valor do $\mathrm{CI}$, resta, em média, quase $70 \%$ de VAB às experiências ecológicas $(69,79 \%)$.

Já o VAL é de R\$ 125.271,35/iniciativa, representando $57,84 \%$ em relação à $\mathrm{PB}$. Ou seja, do total da produção bruta, depois de descontados o CI e depreciações, restam $57,84 \%$ de VAL, em

TABELA 6 - Valor Agregado Bruto (VAB), Valor Agregado Líquido (VAB) e Renda Agroindustrial (RAI), em relação à Produção Bruta (PB) dos SAFEs.

\begin{tabular}{|c|c|c|c|c|c|c|}
\hline SAFEs & VAB (R\$) & VAB (\%) & VAL (R\$) & VAL (\%) & RAI (R\$) & RAI (\%) \\
\hline SAFE 3 & $86.577,98$ & 76,26 & $75.604,98$ & 66,59 & $70.484,66$ & 62,08 \\
\hline SAFE 5 & $52.224,00$ & 94,64 & $38.166,00$ & 69,17 & $30.676,86$ & 55,59 \\
\hline SAFE 6 & $29.177,81$ & 52,16 & $27.845,21$ & 49,78 & $24.105,51$ & 43,09 \\
\hline SAFE 7 & $35.800,99$ & 58,76 & $24.382,99$ & 40,02 & $19.038,66$ & 31,25 \\
\hline SAFE 10 & $663.243,31$ & 49,67 & $651.583,31$ & 48,79 & $583.372,77$ & 43,68 \\
\hline SAFE 11 & $175.666,49$ & 73,04 & $145.596,49$ & 60,54 & $107.146,79$ & 44,55 \\
\hline SAFE 12 & $238.283,39$ & 36,30 & $205.988,39$ & 31,38 & $129.448,69$ & 19,72 \\
\hline Média & 139.029,37 & 69,79 & $125.271,35$ & 57,84 & $105.712,18$ & 49,57 \\
\hline
\end{tabular}

FONTE: Banco de Dados Agregado (2015). 
média/SAFE. Este valor agregado é alto, quando se compara com outros estudos. Por exemplo, Henning (2010) estudou o valor agregado em agroindústrias familiares convencionais (não ecológicas), na mesma região de pesquisa. $\mathrm{O}$ autor auferiu um VAL médio de apenas $20 \%$ em relação à produção bruta. Isso evidencia que a agroindustrialização em bases ecológicas consegue agregar maiores valores a produção, mesmo quando se compara com agroindústrias convencionais familiares.

Ainda, segundo a Tabela 6, a RAI média é de $\mathrm{R} \$ 105.712,18$, correspondendo a $49,57 \%$ da produção bruta gerada por SAFE. Este valor percentual de RAI é alto, quando comparado a outros estudos e sistemas produtivos. Por exemplo, em estudo conduzido na mesma região da pesquisa (MDA, 2007) relacionado à rentabilidade da produção de grãos e commodities agrícolas, encontraram-se valores de renda em torno de 10 a $15 \%$ em relação à produção bruta. Em outro estudo conduzido por Lima et al. (2014) na mesma região, porém em sistemas ecológicos, a RAI auferida foi de $72,5 \%$ em relação a $\mathrm{PB}$, evidenciando o grande potencial de gerar renda destes sistemas produtivos ecológicos. São poucas atividades agropecuárias e sistemas produtivos que possuem uma rentabilidade em torno de $50 \%$, depois de descontados todos os custos de produção. Isto se explica pela agregação de valor que se tem as matérias primas ecológicas, pelo processamento agroindustrial (produção ecológica + agroindústria $=$ alto nível de valor agregado).

\section{Comparando cadeias produtivas ecológicas: alguns indicadores de resultado econômico por área e per capita}

O objetivo desta seção é proceder a comparação de resultados econômicos entre as principais cadeias de produção identificáveis nos SAFEs, utilizando indicadores de custos, valor agregado e renda agroindustrial, bem como imputando custo de oportunidade a força de trabalho familiar ${ }^{5}$. As comparações são desenvolvidas por área ( $\mathrm{R} \$ / \mathrm{ha})$ e per capita ( $\mathrm{R} \$ /$ por pessoa) entre as diferentes experiências.

A Tabela 7 apresenta os custos de produção por hectare $(\mathrm{R} \$ / \mathrm{ha})$ das cadeias de produção dos SAFEs. Isso permite espacializar custos, analisando-os por área. Nota-se que o custo total (CT) médio é R\$ 7.533,25/ha, sendo composto das rubricas do consumo intermediário (CI) médio de $\mathrm{R} \$ 5.348,20$ / ha (corresponde a 58,15\% do CT), depreciações (D) médias de R $\$ 1.113,90 /$ ha $(24,73 \%$ dos CT) e da divisão do valor agregado (DVA) de R \$ 1.071,15/ ha $(17,12 \%$ dos CT). Como mencionada na seção anterior, os custos com CI são maiores, também em média/ha, do que as despesas com D e DVA.

Em estudo conduzido por Reichert et al. (2011) no RS em propriedades ecológicas no Sul do estado, aferiram custos totais de produção médios de $\mathrm{R} \$ 2.025,08 / \mathrm{ha}$, bem abaixo dos $\mathrm{R} \$ \mathrm{R} \$$ $7.533,25 /$ ha encontrados neste trabalho. Entretanto, neste estudo conduzido pelos autores não havia a agroindustrialização associada à produção in natura nas propriedades, rebaixando os custos totais de

\footnotetext{
${ }^{5} \mathrm{O}$ custo de oportunidade é atribuir uma valoração a força de trabalho familiar presente nas unidades, de forma a poder-se comprar a sua remuneração, por exemplo, com um trabalhador urbano. Atribuem-se valores tendo como referência o valor do salário mínimo nacional vigente por ocasião da pesquisa (2014) em relação às UTHs presentes nos sistemas de produção.
} 
produção (são 73,11\% menores), já que a prática da transformação agroalimentar está ausente.

Isso fica bem claro na análise dos custos do SAFE 10, que possui o maior custo de produção de todos os pesquisados. Observa-se que a cadeia dos frangos coloniais com diversificação é a que possui maiores CT, totalizando R $\$ 40.001,98 /$ ha, destacando-se o elevado CI de R \$ 35.753,55/ha. Possivelmente, esta cadeia produtiva abastece-se com insumos e serviços dos mercados agropecuários, desembolsando muito com pagamentos para fora da propriedade, por exemplo, com a aquisição de rações. Isso gera um processo crescente de externalização produtiva da unidade, culminando com o que Ploeg (2008) descreve como mercantilização da agricultura familiar.
Em situação similar a esta cadeia produtiva, estão as dos SAFE 12 (erva mate, peixes e grãos) e 1 (mel, frutas, peixe; diversificado), embora com custos totais bem menores que o SAFE 10 (em torno de $9 \mathrm{mil} / \mathrm{ha})$. Note, que nestes dois casos, os gastos com CI são predominantes sobre os demais custos produtivos (D e DVA), reforçando os argumentos em torno da externalização destas cadeias produtivas. Estes três tipos de cadeias são as que possuem maiores CT de produção.

Em situação intermediária em termos de CT de produção aparece a cadeia de derivados de cana com somente R\$ 6.125,79/ha (SAFE 5); derivados de cana e diversificado com $\mathrm{R} \$ 4.310,34 /$ ha (SAFE 4) e derivados de milho e gado de corte com $\mathrm{R} \$$ 4.290,51/ha (SAFE 2). Em situações de menores

TABELA7 - Valores por hectare (R\$/ha) do Consumo Intermediário (CI), Depreciação (D) e Divisão do Valor Agregado (DVA) e Custo Total (CT).

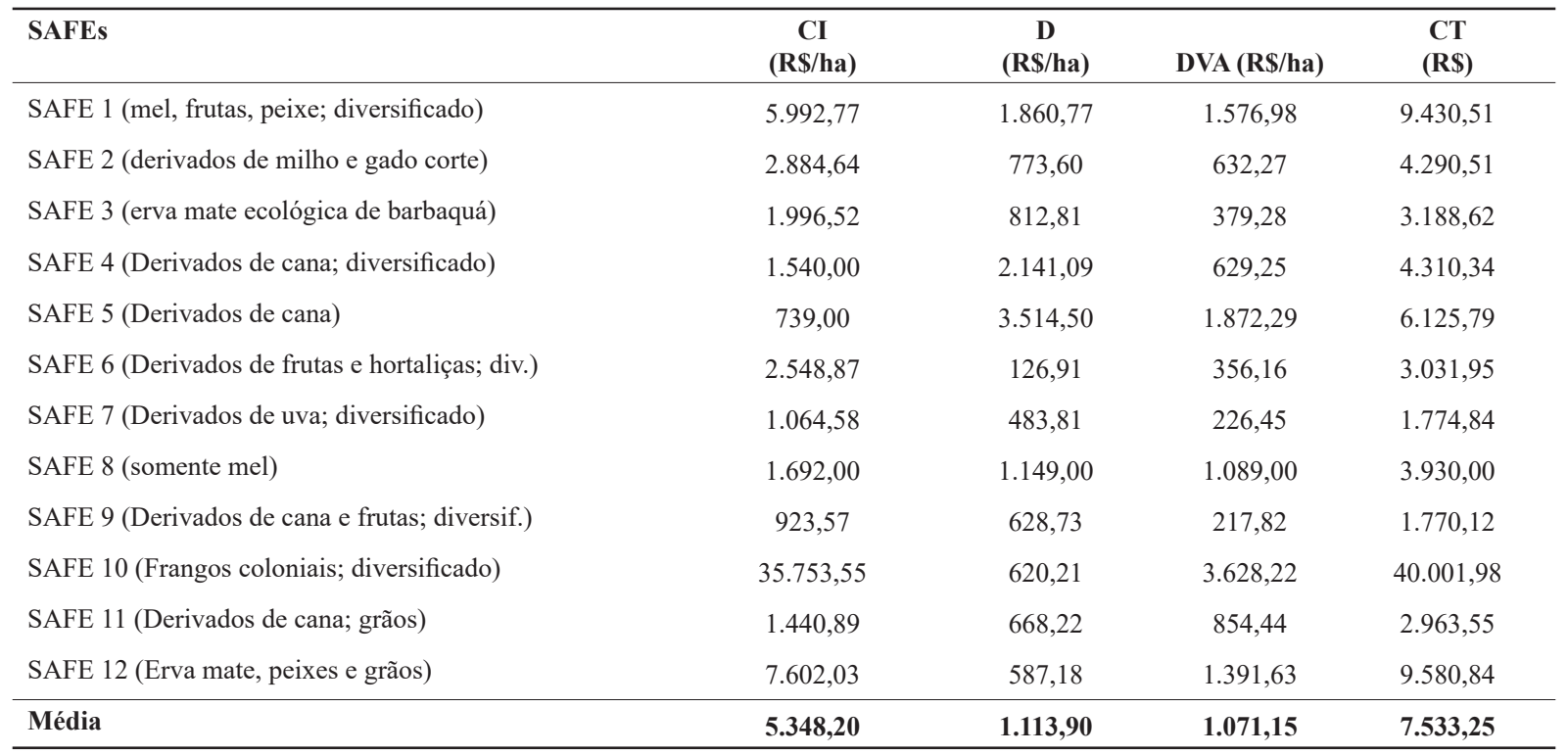

FONTE: Banco de Dados Agregado (2015). 
custos de produção, abaixo de 4 mil reais/ha, estão todas as demais cadeias de produção, destacando-se duas com baixos custos: SAFE 9 (derivados de cana e frutas; diversificado) com apenas R \$ 1.770,12/ha e o SAFE 7 (derivados de uva e diversificado) com R\$ 1774,84/ha. Outro resultado que é possível concluir com base nos dados da Tabela 7 é que o efeito da diversificação não ajuda a reduzir os custos de produção por área dos sistemas ecológicos, já que as propriedades com cadeias produtivas classificadas como diversificadas não possuem menores custos.

A Tabela 8 mostra os dados, por hectare $(\mathrm{R} \$ /$ ha), dos valores da Produção Bruta (PB), Valor Agregado Bruto (VAB), Valor Agregado Líquido (VAL) e Renda Agroindustrial (RAI) das cadeias produtivas. Em média, os SAFEs possuem, por hectare, uma PB de R \$ 15.182,48, VAB de R \$ 9.834,28, VAL de R\$ 8.720,38 e RAI de R\$ 7.649,23. Estes dados evidenciam que em torno de metade dos valores da produção bruta são usados para cobrir os custos de produção antes apresentados, sobrando em torno da metade dos valores de PB como renda/ha.

Note que a RAI média destes sistemas produtivos é de $\mathrm{R} \$ 7.649,23 /$ ha. Este valor pode ser comparado com os dados do Censo Agropecuário (IBGE, 2006). Nas estatísticas censitárias os sistemas produtivos da agricultura familiar geram uma riqueza de $\mathrm{R} \$ 677,00 /$ ha e da agricultura não familiar de $\mathrm{R} \$ 358,00 /$ ha, evidenciando ser maior a rentabilidade destes SAFEs em relação à agricultura familiar $(8,85 \%$ somente da rentabilidade dos SAFEs) e à agricultura não familiar brasileira $(4,68 \%$ somente da rentabilidade dos SAFEs).

Entretanto, há grandes diferenças entre as cadeias de produção predominantes nas diferentes experiências. Em primeiro lugar nos indicadores de desempenho econômico por área está à cadeia de frangos coloniais com diversificação, possuindo valores altos de PB (R\$ 71.032,45), VAB ( $\mathrm{R} \$ 35.278,90)$, VAL ( $\mathrm{R} \$ 34.658,69)$ e RAI (R\$ $31.030,47)$. Como se discutiu anteriormente, esta cadeia produtiva possuí altos custos de produção por área, mas estes se diluem, devido ao enorme volume do valor agregado e renda auferida, fazendo que esta iniciativa possua bons indicadores de rentabilidade. Pelo exemplo desta iniciativa, observa-se que possuir custos de produção elevados não é limitante em termos de reprodução social do sistema ecológico, desde que o mesmo possua bons níveis de valor agregado e renda, conseguindo cobrir os desembolsos e manter margens significativas de rentabilidade.

As duas cadeias produtivas que aparecem em segundo lugar nos indicadores são a do SAFE 8 (somente mel) e do SAFE 1 (mel, frutas, peixe; diversificado), respectivamente em segundo e terceiro postos. As duas cadeias possuem o mel como produto principal e quando se analisa a renda agroindustrial, embora os outros indicadores também sejam muito positivos, nota-se que o mel do SAFE 8 gera R\$15.006,00/ha e o SAFE 1 com mel e outros produtos associados R $\$ 11.371,83$ / ha. Neste sentido, conclui-se que além dos frangos coloniais, o mel e suas associações produtivas são as cadeias produtivas mais rentáveis por área na agricultura de base ecológica.

Como cadeias intermediárias em termos de rendas pode-se elencar o SAFE 2 (Derivados de milho e gado corte), em torno de $8 \mathrm{mil}$ reais/ha, o SAFE 5 (Derivados de cana) com aproximadamente 7,5 mil reais/ha e o SAFE 3 (erva mate ecológica de barbaquá) com 5 mil reais/ha. Nota-se que nestas cadeias intermediárias em rendimentos por área não há um "padrão produtivo" de renda, como no caso 
do mel discutido anteriormente. Todas as demais cadeias produtivas apresentam rendas menores do que 5 mil reais/ha. Especificamente, chama atenção a situação do SAFE 7 (Derivados de uva; diversificado) que possui a menor renda aferida, apenas $\mathrm{R} \$ 806,72 /$ ha e do SAFE 4 (Derivados de cana; diversificado) que possui renda de $\mathrm{R} \$ 1.516,83 /$ ha. Note que nestes dois casos, a produção bruta é significativa porém a renda é baixa, o que sugere que estes dois casos possuem altos custos de produção embutidos em seu processo produtivo. Contudo, a rentabilidade média destes dois sistemas ecológicos ainda é mais elevada quando comparados com os dados do Censo Agropecuário, conforme mencionado à cima.

Nestas cadeias de produção (uva e cana), uma solução seria diminuir estes custos produtivos, aumentar um pouco a escala (que pode estar muito abaixo do mínimo requerido) ou mesmo diferenciar produtos (o que agregaria valor), gerando mais renda. O Caso do SAFE 12 (Erva mate, peixes e grãos) também é interessante de ser observado sob esta ótica. Veja que a PB é de mais de quase $12 \mathrm{mil}$ reais, contudo, a RAI é de apenas 2 mil reais/ha, o que sugere que 10 mil reais são custos de produção. Já o SAFE 9 (Derivados de cana e frutas; diversificado) mostra justamente o contrário, pois possui uma PB de quase 6 mil reais e a renda de mais de 4 mil reais/ha, o que evidencia que mesmo gerando pouca produção bruta, consegue manter uma renda mais elevada do que outras cadeias produtivas, por possuir poucos custos produtivos.

Por fim, os dados da Tabela 8, também permitem afirmar que nem sempre a diversificação produtiva dentro de uma propriedade ecológica ajuda a gerar maiores rendimentos. Nos casos do

TABELA8 - Valores por hectare (R\$/ha) da Produção Bruta (PB), Valor Agregado Bruto (VAB), Valor Agregado Líquido (VAL) e Renda Agroindustrial (RAI).

\begin{tabular}{|c|c|c|c|c|}
\hline SAFEs & PB (R\$/ha) & VAB (R\$/ha) & VAL (RS/ha) & RAI (R\$/ha) \\
\hline SAFE 1 (mel, frutas, peixe; diversificado) & $20.802,34$ & $14.809,57$ & $12.948,81$ & $11.371,83$ \\
\hline SAFE 3 (erva mate ecológica de barbaquá) & $8.409,70$ & $6.413,18$ & $5.600,37$ & $5.221,09$ \\
\hline SAFE 4 (Derivados de cana; diversificado) & $5.827,17$ & $4.287,17$ & $2.146,08$ & $1.516,83$ \\
\hline SAFE 6 (Derivados de frutas e hortaliças; diversif.) & $5.327,71$ & $2.778,84$ & $2.651,92$ & $2.295,76$ \\
\hline SAFE 7 (Derivados de uva; diversificado) & $2.581,57$ & $1.516,99$ & $1.033,18$ & 806,72 \\
\hline SAFE 8 (somente mel) & $18.936,00$ & $17.244,00$ & $16.095,00$ & $15.006,00$ \\
\hline SAFE 9 (Derivados de cana e frutas; diversificado) & $5.815,20$ & $4.891,63$ & $4.262,90$ & $4.045,08$ \\
\hline Média & $15.182,48$ & $9.834,28$ & $8.720,38$ & $7.649,23$ \\
\hline
\end{tabular}

FONTE: Banco de Dados Agregado (2015). 
SAFE 10 (Frangos coloniais; diversificado) e 1 (mel, frutas, peixe; diversificado) isso é verdadeiro, mas há outros casos em que acontece justamente o contrário. Por exemplo, nos SAFES 4, 6 e 7, que são diversificados, a renda é menor. Isso levanta a hipótese, a ser aprofundada em trabalhos futuros, de que a diversificação ajuda no aumento da renda e do valor agregado, mas depende de como o sistema produtivo opera (sobretudo, em termos de economia de custos) e, especialmente, avaliando quais as associações de cadeias produtivas são mais efetivas quando associadas à diversificação.

Na Tabela 9 é possível visualizar os valores per capita da Produção Bruta (PB), Valor Agregado
Bruto (VAB), Valor Agregado Líquido (VAL) e Renda Agroindustrial (RAI) das cadeias produtivas. Isso permite verificar o quanto da riqueza gerada fica para cada pessoa ou UTH que trabalha e vive da produção ecológica, sendo bem mais importante que apurar a riqueza gerada por área, já que neste caso sabe-se quanto cada pessoa adiciona e/ou gera com a produção ecológica em cada uma das cadeias produtivas.

Segundo a Tabela 9, uma primeira coisa que se observa é que os indicadores de desempenho econômico (PB, VAB, VAL e RAI) possuem valores maiores per capita do que os por área, apresentados anteriormente na Tabela 7. Por exemplo, se por área

TABELA9 - Valores per capita da Produção Bruta (PB), Valor Agregado Bruto (VAB), Valor Agregado Líquido (VAL) e Renda Agroindustrial (RAI).

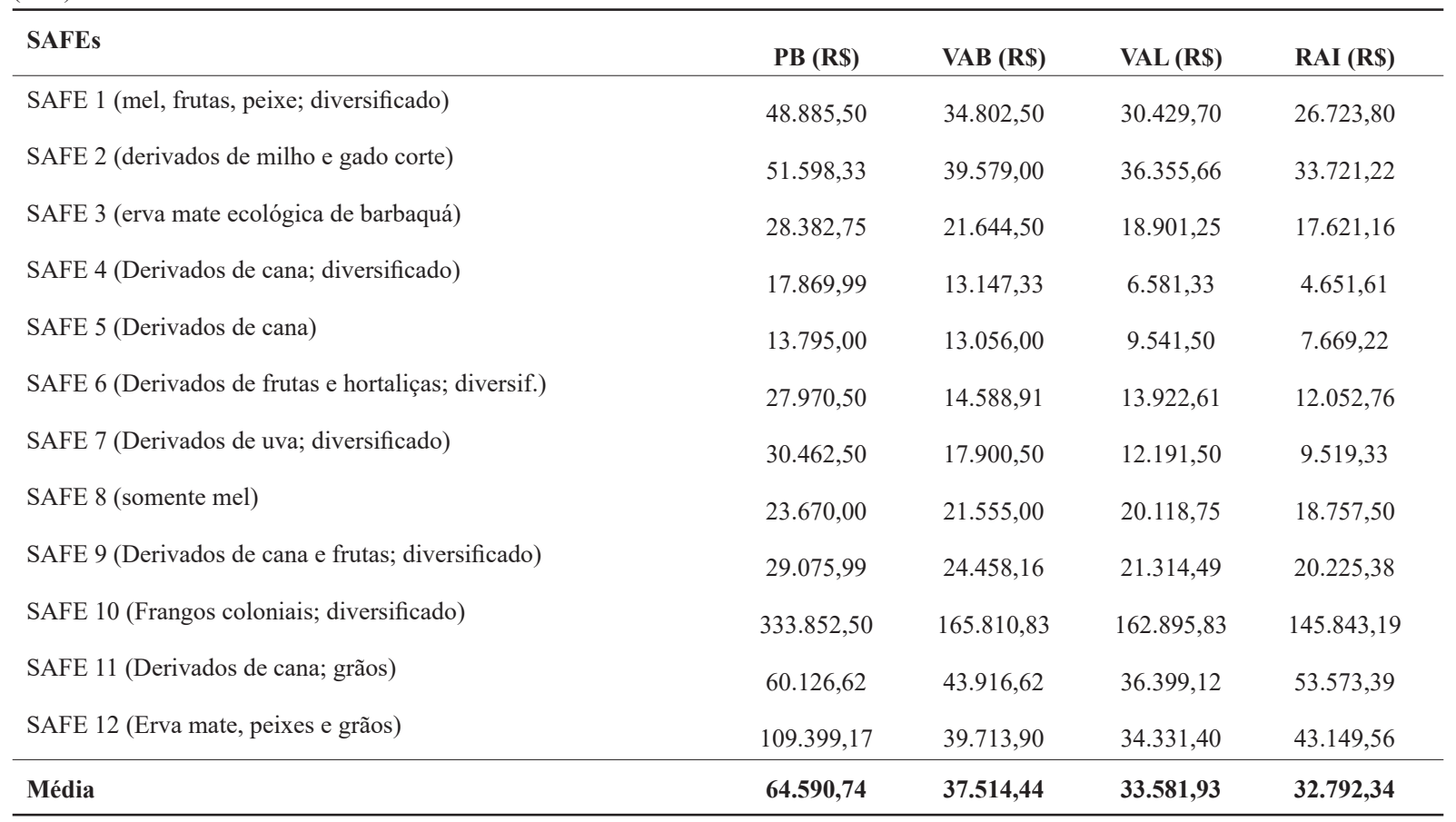

FONTE: Banco de Dados Agregado (2015). 
a RAI média era em torno de 7,5 mil reais/ha; per capita ela chega a quase 33 mil reais/UTH. Isso é devido às unidades familiares possuírem menores números de UTHs dividindo o indicador supracitado, se comparado, a sua área de terras em hectares.

Como indicadores médios das cadeias produtivas tem-se a PB com R \$64.590,74/UTH, VAB de R \$ 37.514,44/UTH, VAL de R\$33.581,93/UTH e RAI de R\$32.792,34/UTH. Observa-se que a renda per capita que fica em mãos dos agricultores é em torno de $50 \%$ da produção bruta média que eles geram em suas unidades; os outros $50 \%$ da produção bruta vai para cobrir o total de custos de produção dos sistemas ecológicos. Isto dito, grosso modo, pois como mencionado nos parágrafos anteriores, estes quatro indicadores variam muito entre cadeias de produção como se analisa na sequência.

Ainda em relação a este valor médio da RAI de R\$ 32.792,34/UTH, ele é considerado elevado quando comparado com outros estudos. Por exemplo, Henning (2010), investigando agroindústrias familiares tradicionais (não ecológicas) na mesma região de pesquisa, chegou a valores médios de RAI de R\$ 13.340,00/UTH, bem menores do que os encontrados. Isso evidencia que os sistemas agroindústrias ecológicos conseguem ter maior rentabilidade per capita do que o mesmo sistema agroindustrial convencional, sendo que no sistema ecológico a RAI é 59,31\% maior.

Segundo a Tabela 9, a cadeia produtiva dos frangos coloniais e diversificada (SAFE 10) aparece com os maiores indicadores de desempenho de todas as experiências com $\mathrm{R} \$ 333.852,50$ per capita de produção bruta. Depois de descontados os custos de produção, esta ainda possui uma renda de $\mathrm{R} \$$ $145.843,19 / \mathrm{UTH}$, mostrando ser a cadeia produtiva dos frangos associada à diversificação da unidade a que mais gera rentabilidade por pessoa ocupada na agricultura ecológica. Este resultado coincide com o anterior (Tabela 8), pois esta cadeia produtiva também possui a maior renda agroindustrial por área.

O SAFE 11 (Derivados de cana; grãos) e o SAFE 12 (Erva mate, peixes e grãos) aparecem em segundo lugar em termos de rendas per capitas, respectivamente, com $\mathrm{R} \$ 53.573,39$ e $\mathrm{R} \$ 43.149,56$. Estas duas cadeias produtivas (cana e erva mate com associações a outras produções) possuem rendas per capitas que podem ser consideradas intermediárias, se comparadas às demais iniciativas. É interessante registrar que,quando calculadas suas rendas por área (Tabela 8), estas duas cadeias produtivas estão entre as menos rentáveis (em torno de 2 mil reais/ha).

Um terceiro grupo de cadeias produtivas com rendas entre 20 e 33 mil reais/UTH, encontram-se o SAFE 2 (derivados de milho e gado corte), o SAFE 1 (mel, frutas, peixe; diversificado) e SAFE 9 (Derivados de cana e frutas; diversificado), com respectivamente, em torno de 33 mil reais, 26 mil e 20 mil reais/UTH. No extremo oposto da Tabela 8 , estão, em ordem crescente de renda o SAFE 4 (Derivados de cana; diversificado) com apenas R $\$$ 4.651,61/UTH, SAFE 5 (Derivados de cana) com R\$ 7.669,22/UTH e o SAFE 7 (Derivados de uva; diversificado) com R\$9.519,33/UTH. No caso das cadeias produtivas constituintes dos SAFEs 4 e 7 há coincidências das mesmas possuírem os menores valores de renda agroindustrial por área e per capita.

No caso da renda per capita das cadeias com diversificação os resultados podem ser interpretados em duas direções diferentes. Há cadeias em que a diversificação aumenta os valores de renda, por exemplo, nas presentes no SAFE 10 (frangos) e 1 (mel), mas no caso das cadeias constituintes de outros SAFEs foram aferidas rendas menores, por 
exemplo, no SAFE 4 (cana) e 7 (uva). Note que estes resultados da diversificação per capita são idênticos ao da renda por área destas cadeias ecológicas, sugerindo haver certo "padrão de rendimentos" das mesmas.

Já a Tabela 10, apresenta o Ponto de Nivelamento (PN) e o Nível de Reprodução Simples $(\mathrm{NRS})^{6}$ das cadeias produtivas e iniciativas. Segundo a Tabela 10 os SAFEs possuem um PN médio de R \$ 51.900,49 em relação a produção bruta gerada. Isso corresponde a quase $30 \%$ dos valores da produção bruta $(27,35 \%)$, que são gastos para cobrir os custos produtivos "variáveis" existentes (DVA
+ CI). Entretanto, estes valores variam por cadeia produtiva. Exemplificando, o SAFE 4 (Derivados de cana; diversificado) possui um PN de R \$34.201,94, o que corresponde a $63,80 \%$ dos valores da produção bruta, que são utilizados para cobrir custos. Lembra-se que este SAFE é um dos que possui os mais baixos indicadores de desempenho econômico (VAB, VAB, RAI), como se analisou anteriormente nas Tabelas 8 e 9, sugerindo que PN altos, fazem os SAFEs geraram valor agregado e renda baixos.

Em outro extremo da Tabela 10, como exemplo também, já que não se discute todas as cadeias produtivas, tem-se o SAFE 10 (Frangos coloniais;

TABELA 10 - Ponto de Nivelamento (PN) e Nível de Reprodução Simples (NRS).

\begin{tabular}{lcccc}
\hline SAFEs & PN (R\$) & PN (\%) & NRS (R\$) & NRS (\%) \\
\hline SAFE 1 (Mel, frutas, peixe; div.) & $24.101,33$ & 24,65 & $18.824,00$ & 38,51 \\
SAFE 2 (Der. milho e gado corte) & $23.745,13$ & 15,34 & $28.236,00$ & 54,72 \\
SAFE 3 (Er. mate eco. barbaquá) & $24.521,33$ & 21,60 & $37.648,00$ & 132,64 \\
SAFE 4 (Der. cana; diversif.) & $34.201,94$ & 63,80 & $28.236,00$ & 158,01 \\
SAFE 5 (Derivados de cana) & $19.733,36$ & 35,76 & $37.648,00$ & 272,91 \\
SAFE 6 (Der. frutas/hort.; div.) & $9.322,69$ & 16,67 & $18.824,00$ & 67,30 \\
SAFE 7 (Der. uva; diversif.) & $28.835,44$ & 47,33 & $18.824,00$ & 61,79 \\
SAFE 8 (somente mel) & $10.492,32$ & 11,08 & $37.648,00$ & 159,05 \\
SAFE 9 (Der. cana e frutas; div.) & $13.392,89$ & 15,35 & $28.236,00$ & 97,11 \\
SAFE 10 (Frangos coloniais; div.) & $87.211,11$ & 6,53 & $37.648,00$ & 11,28 \\
SAFE 11 (Der. cana; grãos) & $65.360,81$ & 27,18 & $18.824,00$ & 62,61 \\
SAFE 12 (Er. mate, peixes e grãos) & $281.887,51$ & 42,94 & $28.236,00$ & 25,81 \\
\hline Média & $\mathbf{5 1 . 9 0 0 , 4 9}$ & $\mathbf{2 7 , 3 5}$ & $\mathbf{2 9 . 8 0 4 , 6 7}$ & $\mathbf{9 5 , 1 5}$ \\
\hline
\end{tabular}

FONTE: Banco de Dados Agregado (2015).

\footnotetext{
${ }^{6}$ No caso da NRS se atribui um salário mínimo/UTH plena ocupada na unidade, incluindo o $13^{\circ}$ salário anual. O salário mínimo considerado para fins de cálculo foi o nacional, de 2014.
} 
diversificado), que possui um PN de R\$ 87.211,11, correspondendo a apenas $6,53 \%$ da produção bruta para dar conta de pagar seus desembolsos "variáveis", evidenciando ser um sistema produtivo ecológico que possui PN baixo, gerando melhores indicadores de desempenho (VAB, VAL, RAI), como se discutiu anteriormente com base nas Tabelas 8 e 9 .

No caso do indicador NRS, a média do para os doze iniciativas é de $\mathrm{R} \$ 29.804,67$. Isso significa que as propriedades que praticam agricultura de base ecológica, se remunerassem sua força de trabalho familiar ao final do processo produtivo, dispenderiam em média 28 mil reais/ano para este feito. Neste caso, a média é bem coerente para a comparação com as diversas experiências, já que a variabilidade dos valores do NRS é pequena entre SAFEs, pois o menor valor se situa em torno de 18 mil reais/ano e o maior 37 mil reais/ano.

Ainda em relação ao NRS atribuído à força de trabalho familiar das experiências, note que quando se calcula o seu percentual fica claro que algumas das cadeias produtivas (SAFEs 3, 4, 5 e 8) não conseguiriam produção bruta necessária para remunerar a força de trabalho existente nas propriedades ecológicas. A pior situação seria a do SAFE 5 (Derivados de cana) que precisaria utilizar de $272,91 \%$ da sua PB para remunerar o trabalho familiar. Entretanto, os demais SAFEs conseguiriam fazer isto, embora com diferentes percentuais da sua produção bruta sendo comprometidos com esse processo. A melhor situação seria, novamente, a do SAFE 10 (Frangos coloniais com diversificação) que utilizaria somente $11,28 \%$ de sua produção bruta para pagar o trabalho familiar.

Estes dados não são preocupantes do ponto de vista dos processos de viabilidade socioeconômica destes sistemas produtivos, já que imputar valores de mercado a força de trabalho familiar (custo de oportunidade) é uma operação de simulação estatística e analítica, que não possui por base um processo social real que acontece no rural, pois o pai de família (administrador da propriedade) não paga mensalmente salários a sua esposa e filhos pelo seu trabalho no sistema produtivo. Assim, o indicador importante de ser analisado é a renda agroindustrial, pois é com esta que o grupo familiar supre suas diversas necessidades ao final do processo de produção e, as "sobras econômicas", em muitos casos, são reinvestidas no sistema produtivo.

\section{Considerações finais}

Este trabalho objetivou mensurar o valor agregado e os custos de produção de sistemas agroindustriais familiares de base ecológica. O grande diferencial destes sistemas produtivos existentes são os atributos ambientais e as diferentes estratégias que os atores sociais mobilizam, de forma proativa, para buscar agregar valor aos seus alimentos e produtos. Os "achados" da pesquisa, permitem algumas considerações importantes, que são esboçadas nestes parágrafos finais do texto.

Do ponto de vista dos custos de produção, a investigação evidenciou que os gastos com insumos e serviços que compõem o chamado consumo intermediário representam o maior custo das experiências, algo em torno de $60 \%$ dos mesmos. Embora elevados, estes figuram muito a baixo da média da agricultura nacional ou mesmo da Região Sul, demonstrando que a agricultura de base ecológica associada com agroindústria consegue se reproduzir com menores valores de consumo intermediário. 
Este achado de pesquisa coincide com o que a literatura internacional tem enfatizado: a busca de sistemas de produção mais econômicos, como uma estratégia de aumentar o valor agregado dos produtos e alimentos comercializados (Ploeg, 2008).

Do ponto de vista da produção gerada nos sistemas ecológicos, a sua base está assentada em dois processos muito importante para a construção da autonomia relativa dos agricultores. Primeiro, a maior parte das matérias primas comercializadas in natura ou usadas para o processamento agroindustrial dos produtos provem das próprias propriedades (em torno de $80 \%$ dos valores da produção bruta). Segundo, as experiências mostram que a principal forma de agregar valor à produção é a agroindustrialização, já que mais de $70 \%$ dos valores da PB obtida provém da comercialização de alimentos e produtos transformados.

A pesquisa também evidenciou que do total dos valores de produção bruta obtidos pelas iniciativas ecológicas, a metade deste valor é utilizado para cobrir os custos de produção. Deste modo restam, depois de descontados os desembolsos (depreciações, consumo intermediário e divisão do valor agregado), aproximadamente $50 \%$ dos valores da produção bruta, que são revertidos em renda agroindustrial, servindo para remunerar os membros da família e manter os sistemas ecológicos em funcionamento. Esta conclusão é muito importante, já que são poucos os sistemas produtivos que possuem níveis tão altos de renda no país. A comparação dos valores encontrados na pesquisa de campo, quando comparado com outros estudos desenvolvidos, mostrou que em nenhum caso a rentabilidade foi maior.

Neste sentido, é possível afirmar que além de possuir menor custo de produção, os sistemas ecológicos também conseguem remunerar de forma mais consistente os agricultores familiares. Esta dinâmica dos custos de produção e indicadores de resultado econômico foi também analisada por área $(\mathrm{R} \$ / \mathrm{ha})$ e per capita (R\$/UTHs), demonstrando existência de um comportamento muito similar das variáveis quando espacializadas ou mesmo quando confrontadas com a riqueza gerada por pessoa ocupada.

O trabalho também procurou comparar as principais cadeias dos sistemas ecológicos e suas associações produtivas, para aferir custos de produção e indicadores de desempenho econômico. Os dados mostram que a cadeia de produção de frangos coloniais juntamente com diversificação da propriedade, embora possua os maiores custos de produção comparativamente a outras cadeias devido ao seu enorme volume de produção bruta obtida, estes custos se diluem, sendo a cadeia que possui os menores gastos percentuais. Esta experiência detém, também, melhores indicadores de valor agregado e renda agroindustrial, evidenciando ser a atividade de criação de frangos associada a outras produções diversificadas as atividades que possuem maiores níveis de agregação de valor, dentre as associações de cadeias de produção comparadas e analisadas.

Quando analisados os indicadores de desempenho econômico por área ( $\mathrm{R} \$ / \mathrm{ha})$ e per capita $(\mathrm{R} \$$ / UTHs) como o valor agregado e a renda agroindustrial as cadeias de produção com valores mais baixos foram da cana, cana com diversificação e uva com diversificação. Estes resultados permitem afirmar que estas cadeias de produção são as que menor valor agregado e renda geram às famílias e sistemas ecológicos. Isto é devido a duas destas mesmas cadeias possuírem os maiores custos de produção: a cadeia da cana com diversificação e uva com diversificação. Isto demonstra, inegavelmente, que valor agregado e renda baixa são advindos dos 
altos custos de produção, que reduzem a margem de rentabilidade destas atividades. Neste caso, a principal medida a ser colocada em prática é realizar uma agricultura mais econômica em desembolsos, que resultaria em indicadores de desempenho econômicos mais rentáveis.

Outra conclusão interessante da pesquisa é que nem sempre a diversificação dos sistemas produtivos ecológicos gera maiores valores agregados e renda agroindustrial às famílias. Neste sentido, os dados são randômicos, sendo que em algumas experiências a diversificação associada a algumas cadeias produtivas aumenta os indicadores de desempenho econômico (frangos e mel) e, em outras (cana, uva, frutas/hortaliças), os reduz. Neste caso, talvez, sejam necessários outros estudos, em outros contextos socioeconômicos e sistemas produtivos, para melhor avaliar o efeito da diversificação sobre a rentabilidade da agricultura de base ecológica.

Estes achados de investigação podem ser importantes para as políticas públicas e agências de desenvolvimento do Estado brasileiro, em diferentes níveis federativos, no sentido que estas podem "desenhar" e conceber programas para, por exemplo, estimular cadeias mais rentáveis ou, alternativamente, apoiar o desenvolvimento das menos rentáveis ou com maiores custos de produção (por exemplo, propor alguma política pública específica). Ou, alternativamente, fortalecer estratégias produtivas e de agricultura de base ecológica que possam agregar maior valor e renda aos agricultores, de forma a melhorar a qualidade de vida das populações rurais que praticam este tipo de agricultura. Fazendo isso, de certa forma, as ações institucionais estariam também beneficiando os consumidores destes alimentos, que estão preocupados em possuir uma vida mais saudável e sustentável ambientalmente.

\section{Referências}

Altieri, M. Agroecologia: a dinâmica produtiva da agricultura sustentável. Editora da UFRGS: Porto Alegre. $4^{\mathrm{a}}$ Edição, 2004, 120p.

Darolt. M. R. Circuitos curtos de comercialização de alimentos ecológicos: reconectando produtores e consumidores. In: Niederle, P. A.; Almeida, L.; Vezzani, F. M. (Orgs.). Agroecologia: práticas, mercados e políticas para uma nova agricultura. Editora Kairós: Curitiba. 2013, pp. 139- 170, $393 \mathrm{p}$.

Conterato, M. A. et al. O impacto do consumo intermediário na agricultura: uma análise comparativa entre agricultura familiar e não familiar - Brasil e regiões Nordeste e Sul. Brasília: Relatório de Pesquisa. IPEA. 2013, 102p.

Friedmann, H. From colonialism to green capitalism: social movements and emergence of food regimes. Research in rural sociology and development, 11, 227-264, 2005.

Gazolla, M.; Niederle, P. A.; Waquil, P. D. Agregação de valor nas agroindústrias rurais: uma análise com base nos dados do Censo Agropecuário. Revista Paranaense de Desenvolvimento, 122, 241-262, 2012.

Gazolla, M. Conhecimentos, produção de novidades e ações institucionais: cadeias curtas das agroindústrias familiares. 292 f. 2012. Tese (Doutorado em Desenvolvimento Rural). Programa de Pós-Graduação em Desenvolvimento Rural, Universidade Federal do Rio Grande do Sul. Porto Alegre, 2012.

Gazolla, M. Redefinindo as agroindústrias no Brasil: uma conceituação baseada em suas "condições alargadas" de reprodução social. Revista IDeAS. 7(2), 62-95, 2013.

Gazolla, M.; Schneicer, S. (Orgs.). Cadeias curtas e redes agroalimentares alternativas: negócios e mercados da agricultura familiar. Porto Alegre: Editora da UFRGS. 2017, 523p.

Glissman, S. R. Agroecologia: processos ecológicos em agricultura sustentável. Editora da UFRGS: Porto Alegre. $4^{\mathrm{a}}$ Edição, 2009, 658p.

Guthman, J. The trouble with 'organic lite' in California: 
a rejoinder to the 'conventionalisation' debate. Sociologia Ruralis, 44(3), 301-316, 2004.

Henning, C. C. Dinâmica agrária e desenvolvimento local: emergência e efeitos econômicos diretos e indiretos da agroindustrialização familiar de pequeno porte em Constantina - RS. 108f. 2010. Dissertação (Mestrado em Desenvolvimento Regional). Universidade Regional do Noroeste do Estado do Rio Grande do Sul. Ijuí/RS. 2010.

Hoffman, R. et al. Administração da empresa agrícola. Editora Biblioteca Pioneira. $6^{\text {a }}$ Edição, 1989, 340p.

IBGE. Censo Agropecuário 2006. Brasília: CD-Roan. 2006.

Lang, T. What is food and farming for: the (re)emergence of health as a key policy driver. In: Butel, F. H.; Mcmichel, P. New Directions in the Sociology of Global Development. Research in Rural Sociology and Development, Vol. 11, Elsevier, 2005.

Lima, A. J. P. et al. Administração da unidade de produção familiar: modalidades de trabalho com agricultores. Editora UNIJUI: Ijui. 2a Edição, 1995, 222p.

Lima, A. J. P. et al. Transição agroecológica e agricultura camponesa: uma análise em termos de sistemas de produção na Região do Médio Alto Uruguai/RS. Anais do X Congresso da Sociedade Brasileira de Sistemas de Produção. Foz do Iguaçu/PR. 2014. 7p.

Long, N. Development sociology: actor perspectives. Routledge, $1^{\text {a }}$ Ed., 285p., 2001.

Maluf, R. S. Mercados agroalimentares e agricultura familiar no Brasil: agregação de valor, cadeias integradas e circuitos regionais. Revista Ensaios FEE, 25(1), 299-322, 2004.

Marescotti, A. Le dimensioni della tipicità dei produtti agroalimentare. In: Agenzia Regionale per lo Svillupo e l'Innovazione nel Settore Agricolo-Florestale (ARSIA) (Org.). Guida per la valorizzazione dei produtti agroalimentare tipici: concetti, metodi e strumenti. Manuale ARSIA. Regione Toscana: Firenze. p. 13-20, 125p., 2006.

Mazoyer, M.; Roudart, L. História das agriculturas do mundo: do Neolítico à crise contemporânea. Lisboa: Instituto Piaget, 2001.
McMichel, P. A food regime genealogy. Journal of Peasant Studies, 36(1), 139-169, 2009.

MDA - Ministério do Desenvolvimento Agrário. Estudo da matriz produtiva do território do Médio Alto Uruguai: diagnóstico para elaboração do Plano Safra territorial. (Apresentado durante plenária do Território do Médio Alto Uruguai, Frederico Westphalen, jun. 2007).

Mior, L. C. Agricultores familiares, agroindústrias e redes de desenvolvimento rural. Chapecó: Editora Argos, 338 p., 2005.

Morgan, K.; Sonnino, R. The urban foodscape: world cities and the new food Equation. Cambridge. Journal of Regions, Economy and Society, 3, 209-224, 2010.

Niederle, P. A.; Almeida, L.; Vezzani, F. M. (Orgs.). Agroecologia: práticas, mercados e políticas para uma nova agricultura. Editora Kairós: Curitiba. 2013, 393 p.

Oliveira, J. A.; Prezotto, L. L.; Voigt, L. Diagnóstico e potencial das agroindústrias familiares do estado do Rio Grande do Sul. Relatório de Estudo Especial. Cooperativa dos Engenheiros Agrônomos de Santa Catarina. Florianópolis: SC, 100p., 2002.

Pellegrini, G.; Gazolla, M. A agroindústria familiar no Rio Grande do Sul: limites e potencialidades a sua reprodução social. Frederico Westphalen: Editora da URI, 2008, 200p.

Ploeg, J. D. van der. Camponeses e impérios alimentares: lutas por autonomia e sustentabilidade na era da globalização. Porto Alegre: Editora da UFRGS. Coleção Estudos Rurais, 372p., 2008.

Touzard, J. M. Construction institutionnelle des indications géographiques et des signes de qualité. Relatório de Pesquisa. Projeto CAPES-COFECUB n. 649-09, 2010, 20p.

Reichert, L. J.; Gomes, M. C.; Schwengber, J. E. Avaliação técnica e econômica de um agroecossistema familiar de base ecológica na Região Sul do Rio Grande do Sul. Revista Brasileira Agrociência, 17(1-4), 123-132, 2011.

Renting, H.; Marsden, T.; Banks, J. Understanding alternative food networks: Exploring the role of short food supply chains in rural development. Environment and Planning. Wageningen, 35, 393-411, 2003. 
Schneider, S. A pluriatividade na agricultura familiar. Porto Alegre: Editora da UFRGS, Coleção Estudos Rurais, 254p., 2003.

Vasconcellos, M. J. E. Pensamento sistêmico: o novo paradigma da ciência. Campinas: Papirus, 2006.
Wanderley, M. B. N. O mundo rural como um espaço de vida: reflexões sobre a propriedade da terra, agricultura familiar e ruralidade. Porto Alegre: Editora da UFRGS. $1^{\text {a }}$ edição. Série Estudos Rurais. 330p., 2009. 